\title{
Setting up a Land Use Cover Change model application for Greater Sydney. Lessons learnt and challenges ahead
}

\section{David García Álvarez}

Departamrnto de Geología, Geografía y Medio Ambiente. Universidad de Alcalá. Spain.

David.garcia@uah.es

\section{Christopher J Pettit}

Simone Zarpelon Leao

City Futures Research Centre. University of New South Wales. Australia

\section{Hedwig Van Delden}

Research Institute for Knowledge Systems. The Netherlands

\begin{abstract}
This chapter presents a Land Use Cover Change (LUCC) model application developed for Greater Sydney. It aims to help decision making in the context of the strategic and spatial planning of Greater Sydney. To this end, the model simulates the dynamics of industrial, low density residential and medium-high density residential areas at spatial resolution of 100x100 $\mathrm{m}$.
\end{abstract}

A series of three Land Use Maps at 30m were specifically developed for the modelling exercise. They determine part of the exercise's limitations, such as the model simplicity and the short timeframe of the simulation (2006-2011-2016). Future efforts should focus on the simulation of population and job growth, exchanges between regions and the application of the model for scenario analysis and impact assessment.

All data of the modelling exercise are openly available at the CityData portal of the City Futures Research Centre.

\section{Key words}

Greater Sydney, Metronamica, Land Use Cover Change modelling, Cellular Automata

\section{Introduction}

Despite its dynamism and having been the object of different strategic plans in the last decades, only a few urban growth model applications have been developed for Sydney. These include the extensive work carried out by Yan Liu (Liu, 2009; Liu and Feng, 2012; Liu and Phinn, 2005, 2004) and the Land Use Cover Change (LUCC) model application set up by Lahti (2008). Both authors carried out model applications that were modest, with a spatial resolution of their models being $250 \mathrm{~m}$. In addition, such previous efforts only modelled the evolution of one land use category, urban land. Such model efforts therefore do not take into account the complex dynamics between different urban land uses as the city evolves over time. Because of those limitations, these models arguably provide limited computationally 
This manuscript has been submitted for publication as a chapter in the Elsevier book "Mapping and Forecasting Land Use. The present and Future of Planning". Subsequent versions of this manuscript, after acceptance and review by the editorial, may have slightly different content. If accepted, the final version of this manuscript will be available via the 'Peer-reviewed Publication DOI'

derived insights into the evolving pattern of the city required by policy makers and urban planners in undertaking strategic planning.

This chapter discusses the development of an open and accessible LUCC modelling application for Greater Sydney, which could facilitate the future planning of the city and its metropolitan area. Such a model would be especially useful to inform the current strategic planning carried out by the Greater Sydney Commission, which was constituted in 2015 (Griffith, 2015). To serve this purpose, such a model application should provide enough detail and replicate the main land use dynamics of interest for policy makers and urban planners.

The Greater Sydney region plan "A Metropolis of Three Cities", launched in 2018, is a comprehensive strategic plan for Greater Sydney that sets out the city vision for the next 40 years (Greater Sydney Comission, 2018). This vision is further developed for the individual districts and documented in the five 20-year District Plans, which have been designed concurrently with the new transport and infrastructure strategies: Future Transport 2056 (NSW Government, 2018) and State Infrastructure Strategy (Infrastructure New South Wales, 2018). All these documents will shape the future outlook of the city. Its implementation is already being monitored and their prescriptions will be revised in the following years. Accordingly, an open and accessible LUCC modelling application for Sydney complying with the needs of urban planners and policy makers would provide an evidenced-based tool to inform throughout this process. It would allow planners and policy-makers to test plan guidelines and compare them with alternative proposals to inform potential plan's revisions as well the implementation of specific elements of the strategy.

In this chapter, we present the initial work carried out to set up a LUCC model for Greater Sydney. Our objective is to lay out the foundations of an open and accessible LUCC model application for Greater Sydney that can be employed and further improved by any user, either from academia or policymaking. To this end, all data employed to generate the model is openly available at the CityData portal ${ }^{1}$.

In the following lines, we first introduce the study area. Then, we justify the model chosen for our exercise and describe the materials employed. Finally, the calibration of the LUCC modelling application set up is described and discussed.

\section{Greater Sydney: a metropolis of three cities}

Sydney is the most populated Australian city and one of the country's economic hubs (NSW Government, 2014). Its growth is expected to continue in the future, doubling its habitants between 2036 and 2056 (Greater Sydney Comission, 2017).

Since its foundation, the city has been rapidly growing and sprawling, especially along the 20th century (Fig. 1). In the first part of the century, the city mostly has grown following the rail lines (Greater Sydney Comission, 2017; Lahti, 2008). Later, the road network has been the main driver guiding the expansion of the urban footprint (Greater Sydney Comission, 2017). The proximity to the coast and the main areas of activity have been also other

\footnotetext{
${ }^{1}$ https://citydata.be.unsw.edu.au/
} 
This manuscript has been submitted for publication as a chapter in the Elsevier book "Mapping and Forecasting Land Use. The present and Future of Planning". Subsequent versions of this manuscript, after acceptance and review by the editorial, may have slightly different content. If accepted, the final version of this manuscript will be available via the 'Peer-reviewed Publication DOI'

important drivers that explain the shape of the current urban footprint of the city (NSW Department of Planning, 2005).

The historic sprawling pattern of Sydney was favoured by the absence of strata scheme legislation until 1961 (Bunker, 2015). In those times, having individual properties in multiple dwelling units was not possible, hampering compact developments (Easthope and Randolph, 2008). Nowadays, Sydney is one of the most competitive housing markets in Australia and worldwide (Greater Sydney Comission, 2017), which makes housing affordability one of the key problems of the city (The Committee for Sydney, 2017). In this regard, the housing market of the city has gone through a financialisation process driven by local and international investors (Morris, 2018).

All those factors have delivered a car-dependent sprawled city in the $21^{\text {st }}$ century, with a low population density and an unbalanced distribution of uses. Accordingly, industrial uses mostly locate in the western city (NSW Government, 2014), whereas services preferentially locate in the city's CBD and Paramatta area (NSW Government, 2014).

To cope with this legacy, authorities have designed in the last decades metropolitan plans that pursued a polycentric and more compact city (Greater Sydney Comission, 2017). However, they have not been very successful to date, as the delivery on the plans' ambitions was mostly trusted to market forces (Pinnegar and Randolph, 2012). Compact developments have been promoted in transport or activity hubs and corridors as well as in brownfield redeveloped areas (Bunker, 2015; Easthope et al., 2014; Troy et al., 2015). In addition, Paramatta has been envisioned as the second city CBD (NSW Government, 2014).

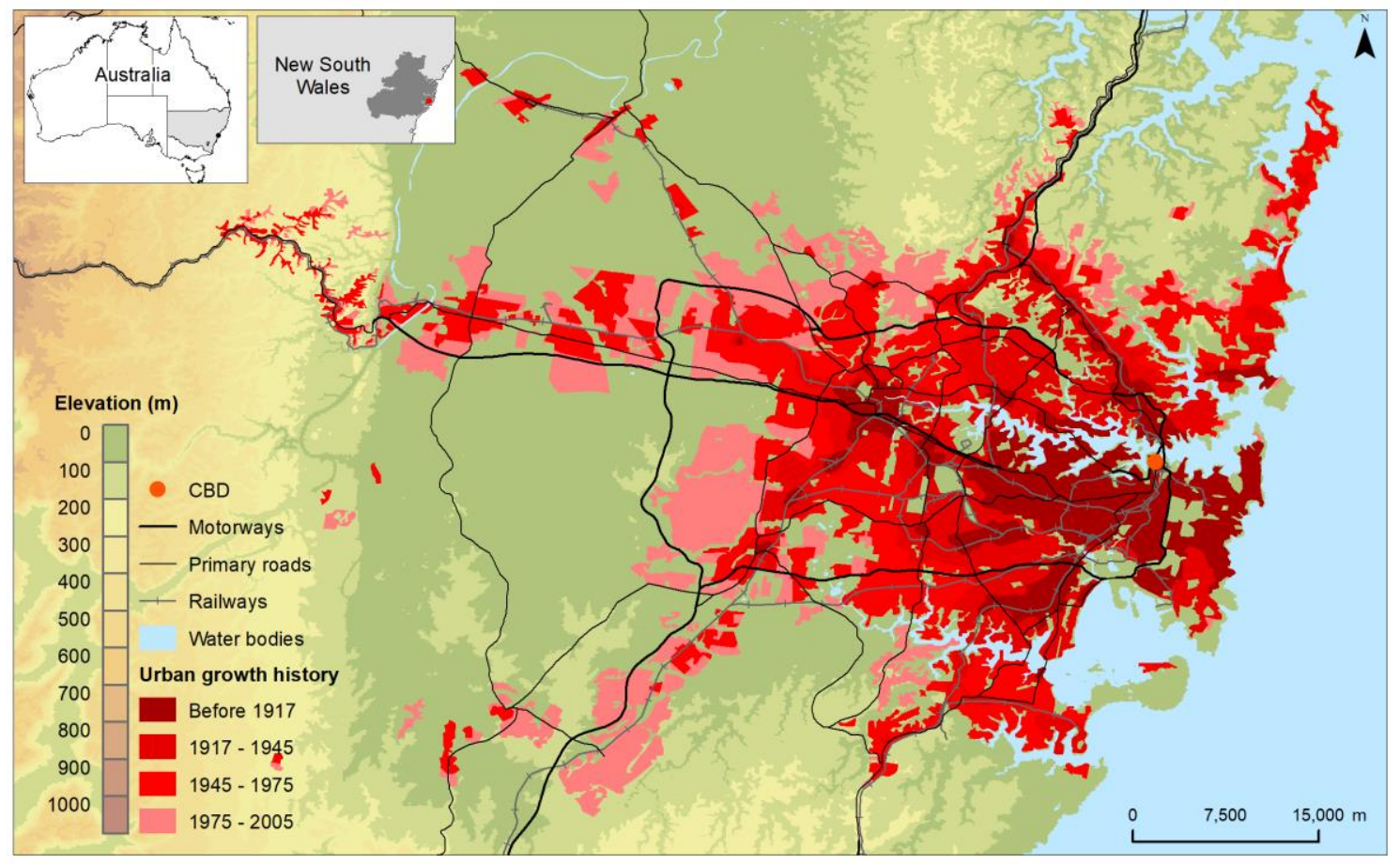

Figure 1. Historical urban growth of Greater Sydney. Sources: City of Cities - A Plan for Sydney's Future (2005); DEM 1 second (Geoscience Australia); Geodata Topo 250K (Geoscience Australia); DERA (IECA).

In 2015, the Greater Sydney Commission (GSC) was constituted as the authority to design a comprehensive strategic plan for the Greater Sydney up to 2056: the "The Greater Sydney 
This manuscript has been submitted for publication as a chapter in the Elsevier book "Mapping and Forecasting Land Use. The present and Future of Planning". Subsequent versions of this manuscript, after acceptance and review by the editorial, may have slightly different content. If accepted, the final version of this manuscript will be available via the 'Peer-reviewed Publication DOI'

Plan. A Metropolis of Three Cities". It envisions a polycentric city region made up of three complementary cities where most residents can reach their workplaces and services in less than 30 minutes (Greater Sydney Comission, 2018).

The GSC is in charge of designing and monitoring the implementation of the plan (Griffith, 2015). However, planning tasks in Australia fall under the state government, which has created and managed the GSC, and the Local Government Areas (LGA) (Australian Goverment, 2011; Greater Sydney Comission, 2017; Griffith, 2015; Hu, 2012). The Greater Sydney region is made up of $36 \mathrm{LGAs}$, which are grouped in five different districts for planning purposes (Greater Sydney Comission, 2018). In addition to the city region plan, the GSC has also developed a specific strategic plan for each of the five districts, which must be implemented by the LGA through their different planning instruments (Greater Sydney Comission, 2017; NSW Government, 2014). It is in this context that we introduce a modelling tool which can be used to model future scenarios of Sydney to support its strategic planning.

\section{The Metronamica modelling framework}

Metronamica (Fig. 2) (Van Delden and Hurkens, 2011) is a constrained Cellular Automata (CA) model based on the work developed by White et al. (1997). CA models are commonly employed in urban environments, as they fit the basic rules that usually guide urban growth (Santé et al., 2010). According to CA theory, the state of a unit is dependent on the state of neighbourhood units.

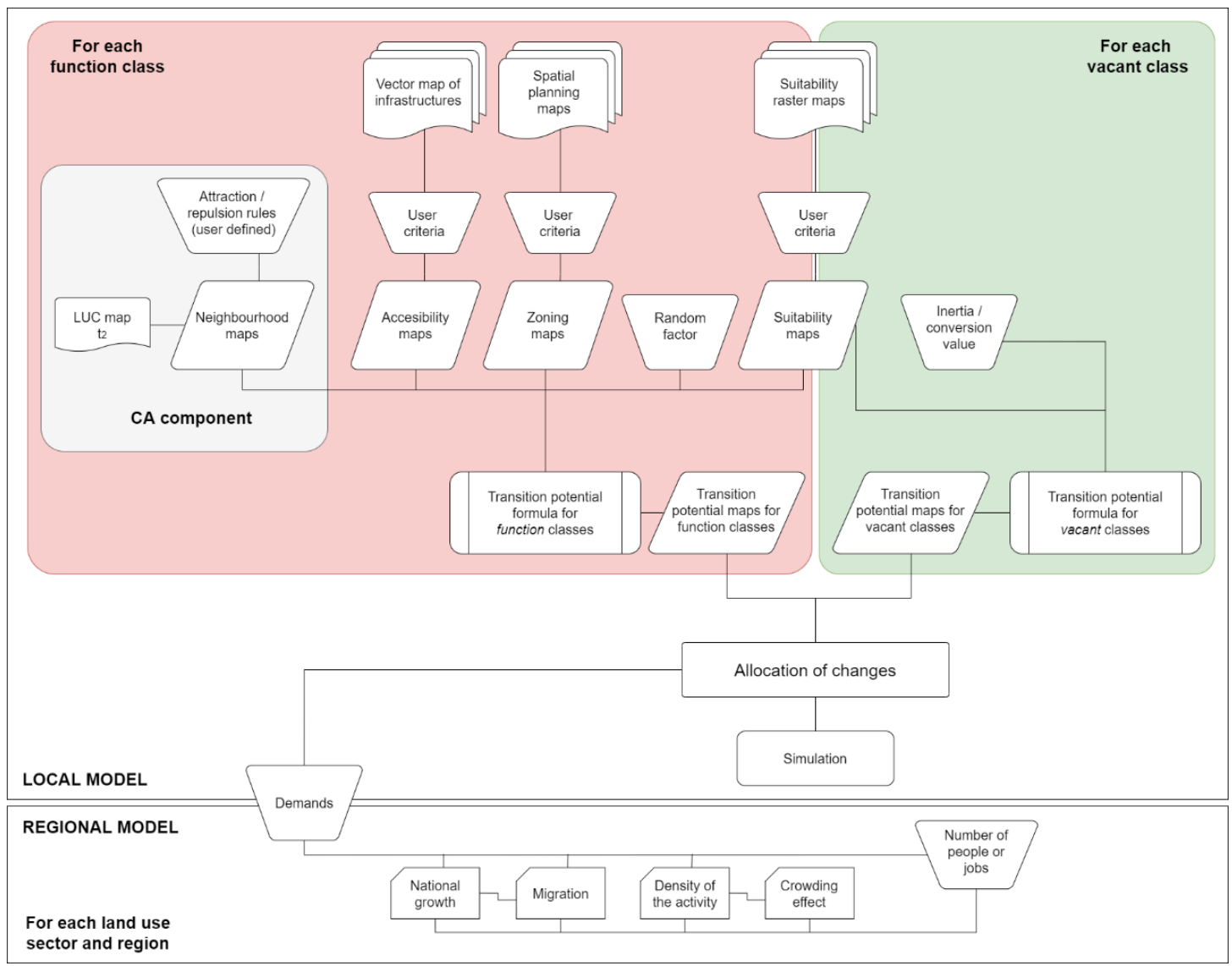

Figure 2. Graphic representation of the Metronamica Land Use Change modelling framework. 
This manuscript has been submitted for publication as a chapter in the Elsevier book "Mapping and Forecasting Land Use. The present and Future of Planning". Subsequent versions of this manuscript, after acceptance and review by the editorial, may have slightly different content. If accepted, the final version of this manuscript will be available via the 'Peer-reviewed Publication DOI'

Metronamica works at multiple scales. At the regional level, the modelled area is split in different regions, each one with a specific level of population and employment activity. The model at regional level is a gravity-based or spatial interaction model that simulates migration between regions and allocates the overall growth over the regions. Calculated population and employment figures and next translated into LUC demands. At the local level, Metronamica allocates LUC demands in a matrix of cells, where each cell is classified as a unique category.

There are three types of categories: functions, which are actively modelled; vacants, which are passively modelled; and features, which remain invariant during the simulation. Function classes have an exogenous demand (from the regional model) and their allocation is based on four different factors, plus a random component: neighbourhood, accessibility, suitability and zoning. The neighbourhood factor incorporates the CA component in Metronamica and allows to define the influence that any other category of land use exerts on each function class. Vacant classes are modelled based on the combination of a suitability, an inertia and a conversion factor.

For function and vacant categories, a transition potential map is obtained after the combination of all factors. Function classes are allocated based on the levels of population and employment activity per region. Then, vacant classes are allocated in the remaining space.

Metronamica is a stable and tested modelling framework, already applied to many urban areas across the world (Hewitt et al., 2014; Kim and Batty, 2011; Lahti, 2008; Páez and Escobar, 2017; Van Delden et al., 2011). There is plenty of technical information available (RIKS, 2012; Van Delden and Vanhout, 2018), as well as a community of users able to help with the model usage. In addition, its interface is user-friendly. This makes its usage and application in policymaking easier. That is why it has been the chosen framework to set up our LUCC model application for Greater Sydney.

\section{Data}

\section{LUC maps}

As a pattern-based LUCC model, one of the key inputs of Metronamica is a series of historical and coherent LUC maps. LUC maps providing enough spatial and thematic detail for local applications were not available for Greater Sydney. We therefore decided to create our own series of LUC maps through supervised classification of Landsat imagery for the years 2006, 2011 and 2016 (Fig. 3). In a post classification stage, new categories were obtained by combining the classified maps with auxiliary information: census data the mesh block level, New South Wales (NSW) Topographic Map, Land Zoning map from the NSW Planning \& Environment Department and Strata Schemes Data provided by the City Futures Research Centre. 
This manuscript has been submitted for publication as a chapter in the Elsevier book "Mapping and Forecasting Land Use. The present and Future of Planning". Subsequent versions of this manuscript, after acceptance and review by the editorial, may have slightly different content. If accepted, the final version of this manuscript will be available via the 'Peer-reviewed Publication DOI'

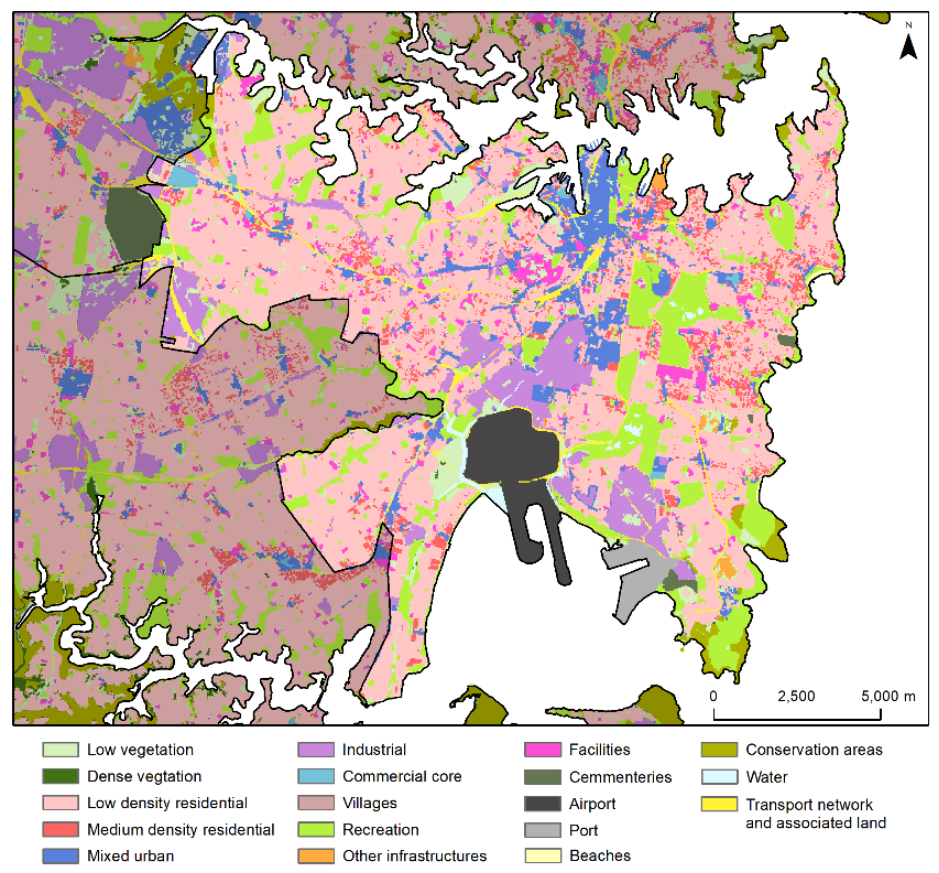

Figure 3. Land Use Map of Greater Sydney (2016) at 30m spatial resolution for the Eastern City District.

The spatial resolution of the maps was the one of the Landsat imagery: $30 \mathrm{~m}$. The thematic resolution of the maps was decided according to the model conceptualization. Thus, this step of data generation was parallel to the one of model conceptualization.

Factors

Model factors were built based on different sources of data. For the accessibility factor, roads and train stations were obtained from the Digital Topographic Database (DTDB) of New South Wales (NSW). Activity centres were mapped from the Greater Sydney Draft District Plan Map Atlas (2016). For the suitability factor, slope and distance to the coastline maps were obtained from the SRTM-derived 1 Second DEM (Geoscience Australia) and the DTDB of NSW respectively. For the zoning factor, different sources from the Department of Planning and Environment of the NSW government were employed: Environment Planning Instrument - Land Zoning, Future Residential Growth Area, and Employment Lands Development Monitor (ELDM).

\section{Model conceptualization}

\section{The modelled transitions}

The main purpose of the developed LUCC model application for Greater Sydney is to inform the planning process of the city. Sydney's changes, which are object of planning, are mainly explained by two processes: urban sprawl and urban densification.

Three categories are actively modelled as functions in our model to replicate those processes: low density residential, medium to high density residential and industrial areas. The changes and dynamics from other mapped categories, such as mixed urban, commercial core or facilities, could also be of interest to model the city's main processes of change. However, these categories only affect a small portion of land and do not experience a critic level of 
This manuscript has been submitted for publication as a chapter in the Elsevier book "Mapping and Forecasting Land Use. The present and Future of Planning". Subsequent versions of this manuscript, after acceptance and review by the editorial, may have slightly different content. If accepted, the final version of this manuscript will be available via the 'Peer-reviewed Publication DOI'

change as to objectively study and explain their LUC change in the considered period of time. In addition, we lack data to create some of the factors that explain their changes.

To model urban densification, only two categories of residential density are considered. Medium and high-density residential areas were grouped in only one category. High-density residential areas are very limited and, in the main activity hubs, can be assimilated with mixed urban areas. Therefore, its simulation as a separated function category would face the same problem pointed out for categories like mixed urban or commercial.

The urban sprawl takes over vacant land, mainly agricultural and natural vegetation areas. Three categories in our maps fall under these criteria: low vegetation, dense vegetation and conservation areas. Only the two first were considered vacant categories in our model, as conservation areas are legally protected and, therefore, will not be object of any urbanization process.

\section{The timeframe}

To correctly model LUC dynamics, long time periods are usually preferred. They allow to better understand and analyse the structural processes behind the modelled system. They are also better suited to rule out one-off events. Nonetheless, its extension to the past should never surpass the period over which the modelled system is explained by similar processes and rules.

For Greater Sydney, we can observe a similar pattern of growth, explained by the same factors, since a few decades ago. However, the timeframe of our simulation is mainly limited by data availability. The three dates for which we produced LUC maps are those for which census data at the mesh block level is available. This has been a key source of information to produce our input LUC maps.

\section{The spatial detail}

For local applications, a minimum degree of spatial detail is required to make the modelled system realistic. However, the original spatial resolution of the Sydney's LUC maps, 30m, was too detailed. The model software struggled when managing the maps, working very slowly. In addition, at this spatial resolution the model did not perform well as a $30 \mathrm{~m}$ resolution touches upon the conceptual limits of the modelled dynamics.

To correctly model LUC changes of medium to high density residential areas, a coarser spatial resolution of $100 \mathrm{~m}$ delivered better results. This coarse resolution allows to group new residential developments in big patches and diminishes the role that the CA component plays to simulate the modelled pattern. Although compact developments usually take place around activity and transport hubs and corridors, they do not usually present a full contiguity. Simplifying the landscape at coarser resolutions, through a generalizing resampling method (majority rule) (Fig. 4), allowed to better fit the pattern of this category to the model behaviour. 
This manuscript has been submitted for publication as a chapter in the Elsevier book "Mapping and Forecasting Land Use. The present and Future of Planning". Subsequent versions of this manuscript, after acceptance and review by the editorial, may have slightly different content. If accepted, the final version of this manuscript will be available via the 'Peer-reviewed Publication DOI'

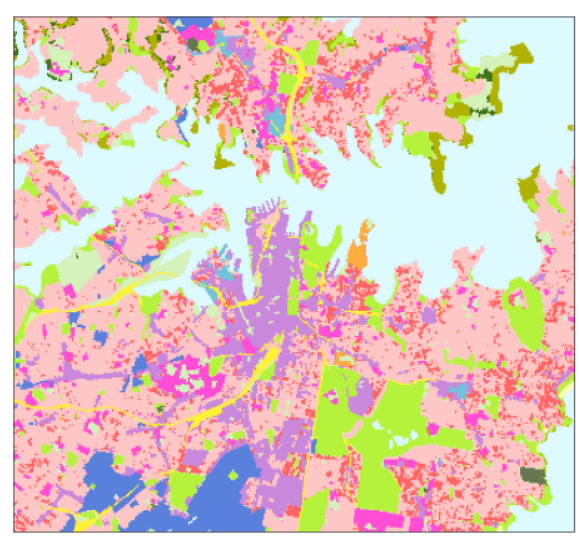

$30 \mathrm{~m}$ Original resolution
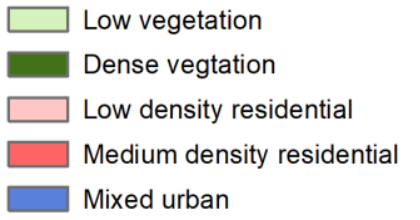

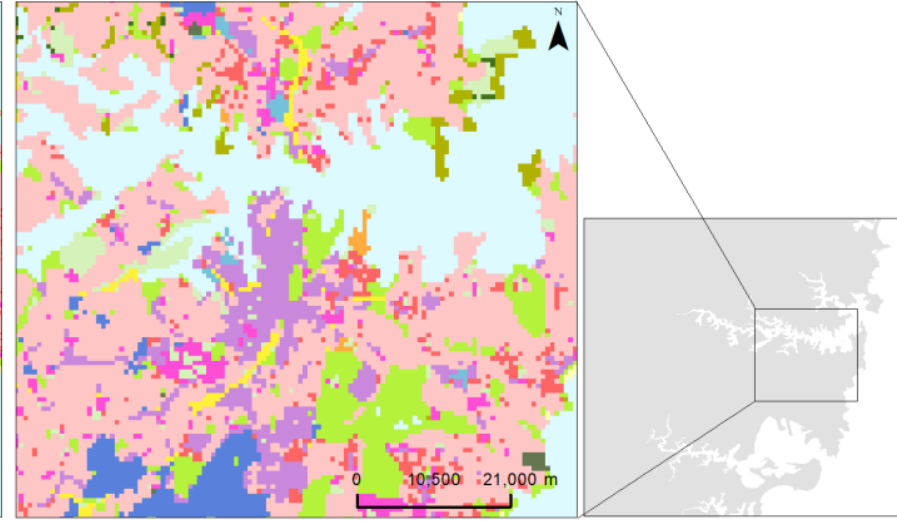

100m Majority rule resample

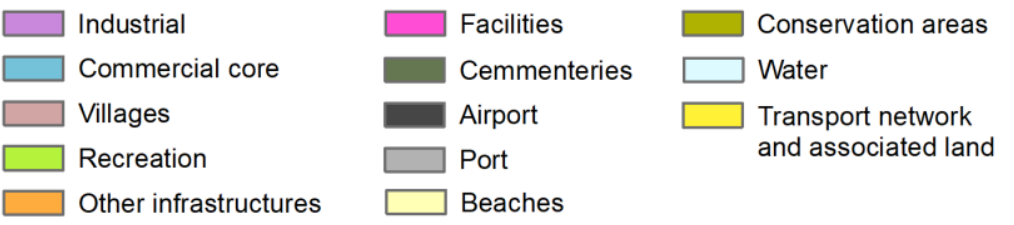

Figure 4. Comparison of the Land Use Map of Greater Sydney (2016) at the original resolution (30m) and resampled at $100 \mathrm{~m}$ through the majority rule method for an example area of Greater Sydney.

The system regionalization

Greater Sydney is a large region made up of different parts with contrasted dynamics. The city planning envisions a polycentric city with multiple complementary centres of activity. In addition to the global plan for Greater Sydney, the current planning instruments split the city in five districts (Fig. 5).

Specific objectives are envisioned for each district. In addition, scenarios of jobs and population are also provided for each district. Accordingly, we have regionalized our global model for Sydney following the district division proposed by the Greater Sydney Commission. This allows to model the specific dynamics of each district and to better adapt the model application of the planning approach of the city. 
This manuscript has been submitted for publication as a chapter in the Elsevier book "Mapping and Forecasting Land Use. The present and Future of Planning". Subsequent versions of this manuscript, after acceptance and review by the editorial, may have slightly different content. If accepted, the final version of this manuscript will be available via the 'Peer-reviewed Publication DOI'

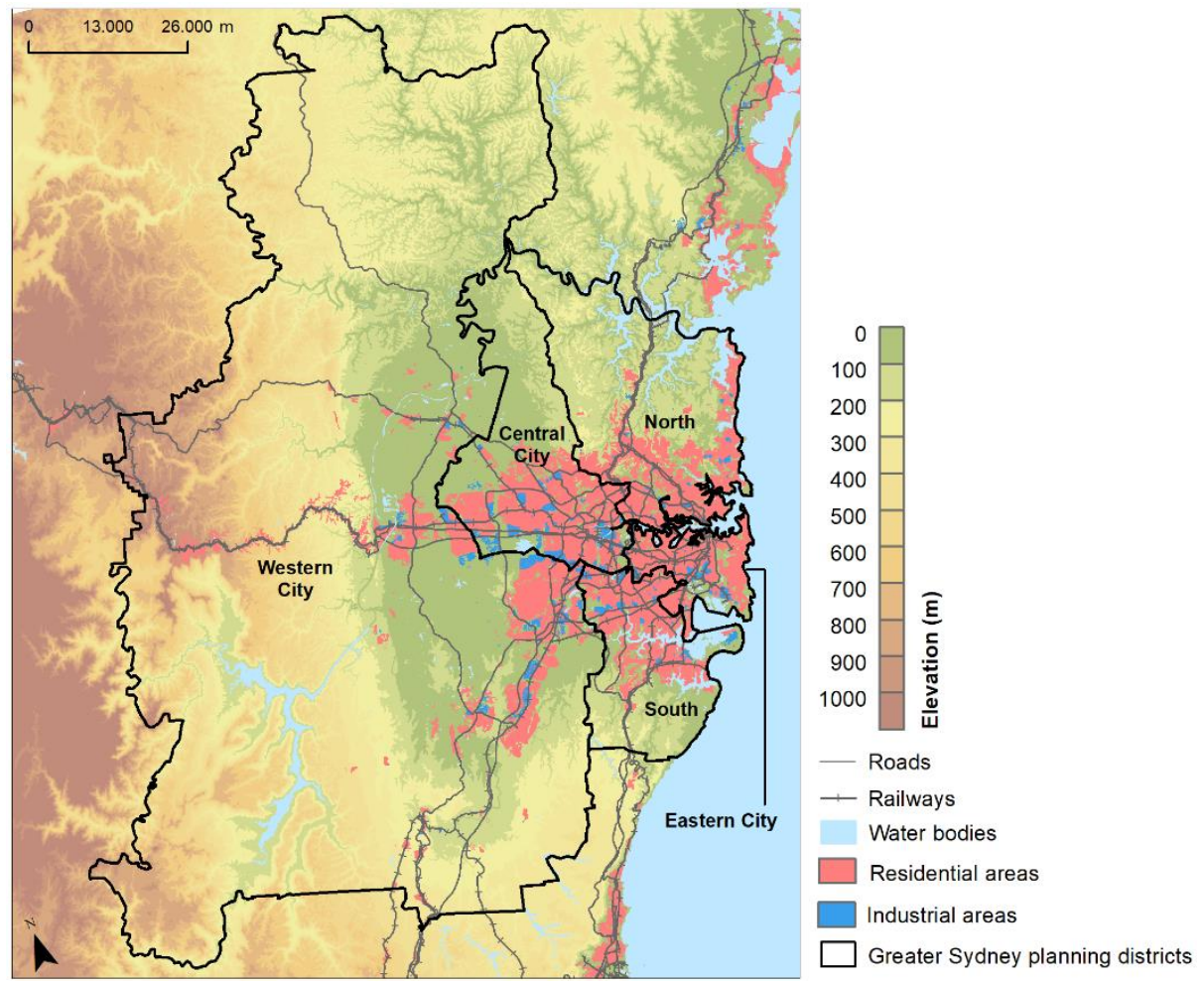

Figure 5. Limits of the planning City Districts proposed by the Greater Sydney Commission: Eastern City, North, South, Central City and Western City.

\section{The factors}

Model factors are determined by data availability. Land price is one of the main factors driving urban growth in cities, especially for residential uses. However, spatial and up-to-date detailed data of land price is usually scarce or not available. In addition, this factor varies with time and land use changes. When considered, it should be modelled as well, as done by Furtado et al. (2012).

Some factors correlate with land price and can provide similar information, like accessibility or availability of vacant land. People like to live close to where jobs and services are. Areas closer to accessible centres and better connected to them are therefore more demanded and expensive. On the other hand, large pockets of undeveloped land in the edges of the city are usually cheap, its higher or lower price determined by its accessibility and closeness to other facilities and services.

The attractiveness of residential areas, and its price, is also usually determined by their environmental quality and proximity to green and open spaces, as well as their distance to some essential services such as schools. In Sydney, areas closer to the beach or the Harbour are premium localities which command a significant property price. People opting for larger and more affordable residential properties usually move towards the fringe of the city whilst those wishing to be close to transport infrastructure and city amenities will consider medium and high-rise living. These price dynamics have been previously modelled and provide important considerations into the future growth of the city (Lieske et al., 2021; Chris Pettit et al., 2020). 
This manuscript has been submitted for publication as a chapter in the Elsevier book "Mapping and Forecasting Land Use. The present and Future of Planning". Subsequent versions of this manuscript, after acceptance and review by the editorial, may have slightly different content. If accepted, the final version of this manuscript will be available via the 'Peer-reviewed Publication DOI'

To account for all of the above, we have included in our model different factors: proximity to the road network, differentiated according to the road hierarchy; proximity to train stations, differentiated according to the station relevance; proximity to activity centres, differentiated according to their importance; proximity to the coastline; proximity to other uses such as facilities, recreation or conservation areas (CA component); and available pockets of undeveloped zoned land, classified according to their size.

Slope was also included as a factor for urban growth in our model, although its importance is very low. With regards to the CA component, we have considered for the three function classes self-attractiveness rules. Residential and industrial land tend to locate where previous residential and industrial land is already located. This is closely correlated with the previous factors of accessibility and proximity to services and facilities. In addition, we have also included a conversion from low density to medium-to-high density residential, as the second use takes over the first in those areas of the city better serviced, with better accessibility and where compact developments deliver a better financial profit.

Finally, zoning is one of the key drivers explaining where new uses can be allocated. In planned cities, changes happen according to what plans and rules prescribe. In Sydney, the specific location of new developments is therefore affected by local and regional plans. Thus, a model like the one we set up allows to see how changes of these planning documents may affect the future shape and evolution of the city.

\section{Model calibration and validation}

We calibrated our application for the period 2006-2011. The application was further validated with independent data not used in the calibration phase, for the year 2016.

The calibration followed the standard procedure usually employed in Metronamica (Hewitt et al., 2014; Van Delden et al., 2018). It is a manual calibration, according to the classification proposed by Van Vliet et al. (2016). The model was initially calibrated based on user and expert knowledge and later improved on a trial and error basis based on visual inspection and the information provided by different indices of agreement: Kappa (K), Fuzzy Kappa (FK), Kappa Simulation (KSim), Fuzzy Kappa Simulation (FKSim) and different spatial metrics such as clumpiness.

Kappa indices measure the agreement between simulated and reference landscapes or changes, corrected by the agreement expected by chance (Van Vliet et al., 2011). Whereas Kappa allows to assess how well persistence was simulated, Kappa Simulation specifically assesses how well LUC changes were simulated (García-Álvarez et al., 2019). Fuzzy Kappa indices account for the degree of spatial mismatch (Van Vliet et al., 2013). That is, they consider as partial hits changes located close to the areas that actually changed in the reference maps. Spatial metrics quantify the pattern of LUC maps and, therefore, allow to compare the difference pattern showed by simulated and reference maps (Tong and Feng, 2020). A benchmark with changes randomly allocated (Hagen-Zanker and Lajoie, 2008) was also used as a reference to compare the simulation.

Results showed good fit between the simulation and the reference map, even better in the validation stage than in the calibration. A Ksim of 0.173 in the calibration stage was almost doubled in the validation stage (0.297). FKSim values reveal for the two stages good scores (0.233 and 0.354), with many changes allocated close to changes in the reference map. High 
This manuscript has been submitted for publication as a chapter in the Elsevier book "Mapping and Forecasting Land Use. The present and Future of Planning". Subsequent versions of this manuscript, after acceptance and review by the editorial, may have slightly different content. If accepted, the final version of this manuscript will be available via the 'Peer-reviewed Publication DOI'

scores of FK $(0.998,0.996)$ inform us how persistence was correctly modelled in the two cases. Finally, differences in the spatial metrics for the simulated maps in the calibration and validation stages are very low when compared with the reference maps. Clumpiness difference in the calibration phase is only 0.002. Mean fractal dimension difference in de calibration phase is -0.16 . In the validation phase, differences for both metrics are 0.001 and 0.001 respectively.

When compared with the benchmark we used as reference, our simulations clearly outperformed them. KS and FKS for the benchmark were 0.1 in the calibration and validation phases. FK was 0.996 and 0.992 in the calibration and validation phases respectively. Clumpiness and mean fractal dimension differences between the benchmarks and the initial maps were much higher than in the simulations: -0.0242 and -0.0279 in the case of clumpiness and -0.162 and 0.010 in the case of the mean fractal dimension.

\section{Discussion}

Our model application for Greater Sydney is able to simulate the main LUC processes happening across the city. It performed well according to the different criteria we have used to evaluate the simulation. However, some issues may arise regarding the level of abstraction chosen to represent the specifics of the urban dynamics of Greater Sydney. Pending tasks refer to the calibration of the regional model based on population and jobs statistics as well as the production of scenarios for planning purposes.

In the next section, we discuss the main application issues and possible ways to address them. We also discuss the future work with the model and its potential for practical use.

\section{The conceptual model: Too simple?}

There is a common debate in LUCC modelling regarding the level of model complexity. Whereas some authors prefer complex models, because they may capture the complexity of real processes better, other authors advocate for simpler models, as they are usually more transparent and understandable (Goodspeed et al., 2017; Christopher Pettit et al., 2020). This makes them accessible to a wider community of users.

Our model application fits the second group. We have simplified the LUC dynamics of Sydney in a model application that is very easy to use and understand. However, this comes with some disadvantages. Our application can be only used to assess the general pattern of growth of the city, evaluating for example the different directions and hotspots of urban growth. However, when going into the detail, it is difficult to determine some specific questions like to what extent the urban densification process results in a specific number of new population and households for a specific area.

The model complexity is partially determined by the availability of input data. In this regard, for LUCC models working on the base of LUC patterns, the lack of a temporally coherent and detailed series of LUC maps is a key limitation. For Greater Sydney we had to create our own series of LUC maps, which could not be extended back before 2006. The developed conceptual model for Greater Sydney is very affected by these and other restrictions from input data. 
This manuscript has been submitted for publication as a chapter in the Elsevier book "Mapping and Forecasting Land Use. The present and Future of Planning". Subsequent versions of this manuscript, after acceptance and review by the editorial, may have slightly different content. If accepted, the final version of this manuscript will be available via the 'Peer-reviewed Publication DOI'

The modelling and understanding of urban densification are very limited because of the information provided by input LUC maps, which only give a general overview of the process. The changes on some uses like commercial or mixed urban are rarely captured in our series of maps. These changes are usually a few. If not well captured, it is almost impossible to correctly simulate them. There is not a critical mass of changes to extract common rules and patterns of change from them. Finally, the changes on the industrial uses are also affected by some limitations, as only new industrial soil developed in already zoned industrial areas according to the planning documents is considered in our series of maps. This limits many other and less relevant industrial developments that may emerge throughout the city.

The production of a new historical series of LUC maps with higher thematic and spatial detail, as well as with better accuracies, could be one of the solutions to the previous problem. However, this requires the availability of detailed auxiliary data sources, able to provide information about historical land use changes.

Opting for other modelling frameworks, which not only focus on land uses, but also on counts of population and jobs, may be an alternative approach to solve some of the limitations stated above, such as the provision of details about the urban densification process.

Wu and Martin (2002) and Wu et al. (2011) developed models focusing on the simulation of population counts instead of land uses. These approaches can only simulate population changes, but not changes in land uses, which are also very relevant for spatial planning. Van Vliet et al. (2012) proposed a modification of Metronamica that allows to simulate population and jobs per cell in addition to land use states. This would be an effective solution that would provide more detail to our model, giving more insight to potential users about the LUC dynamics of the city. However, it requires the availability of spatially detailed population and jobs data. Whereas the first is currently possible in the case of Greater Sydney, the second should be explored and would ideally require the production of a specific dataset to fit the model input data requirements.

\section{The regionalization of Greater Sydney}

We have only calibrated the local model of our application. At the regional scale, although we have split Greater Sydney in five different regions with specific land use demands, we have not modelled the flows of population and economic activity between regions.

Simulating the exchanges of population and jobs across the different regions is the next step in the application development. It will add more independence to the model application, which will not rely on the land use demands set up by the user. Notwithstanding, the standard Metronamica modelling framework can present some limitations when modelling regional flows of population and activity for the simulated categories.

At the regional scale, Metronamica simulates the number of jobs and population to be allocated in each region. Then, the model translates those numbers in actual land use demands. To simulate the number of jobs and residents per region, the model considers for each region the inertia of the activity, the migrated activity from other regions, the national growth and the density of the population and jobs per area. 
This manuscript has been submitted for publication as a chapter in the Elsevier book "Mapping and Forecasting Land Use. The present and Future of Planning". Subsequent versions of this manuscript, after acceptance and review by the editorial, may have slightly different content. If accepted, the final version of this manuscript will be available via the 'Peer-reviewed Publication DOI'

Metronamica models the distribution of the external migration to the entire modelled area over the regions in the area in the same way as it calculates the internal migration flows. However, this does not fit well with the dynamics of Greater Sydney, especially when considering the overseas migration. In terms of internal migration, many people move from the Eastern city to inner places looking for permanent and cheaper accommodation. However, international migrants mostly move to the Eastern city, resulting in high density and compact developments. Because of the importance of overseas migration for Greater Sydney as well as internal migration and both groups valuing different aspects and hence different regions, one mechanism to distribute both the internal and external migration does not work well for a city like Greater Sydney.

As a future improvement to the Metronamica modelling framework, it would be useful if the internal migration and the division of the external migration over the regions could be modelled as separate processes, each with its own set of calibrated parameters. Another option might be to treat the local population and the international migration as different population sectors so can sector can be parameterised to reflect the observed behaviour.

On the other hand, the two population land use categories of our model (low density residential, medium to high density residential) are characterized by different densities of population per pixel. Metronamica requires the user to define different population sectors when the density per pixel varies. This forces us to assign a specific number of people to our two residential modelled land uses, which is not easy. In addition, when splitting the population demands between sectors to account for the different density values, the model does not allow to transfer the population from one sector to the other. However, when low density residential areas become compact developments, that population does not migrate, but increases.

Because each land use is characterized by a homogenous density, i.e. number of people or jobs per area, we must assume that the population density is the same across all pixels for the medium to high density residential case. However, that is not the case. Whereas some compact developments may be more limited, with only a couple of floors or a few neighbours, others may be massive, hosting tens of people under the same roof. A possible solution would be to create more density classes, but if the data available is limited, especially regarding the denser classes, that would pose issues on this solution too.

The Activity-based version of Metronamica proposed by Van Vliet et al. (2012) could solve that issue. In this modified version of Metronamica, each cell has its own density. However, this approach requires an extra data and calibration effort. In addition, the extra detail introduced does not necessarily lead to extra accuracy in the model results.

WISE (Van Delden et al., 2012), an integrated spatial decision support system that incorporates the Metronamica CA-based land use model, also gives modellers more flexibility to define different densities per LUC categories. These can vary with time. This model also allows the proportion of population to be allocated in each land use sector to vary with time, giving planners ample opportunity to explore different densification processes. Complementing the approach used in WISE with the Activity Based Metronamica (Van Vliet et al., 2012) would give an answer to the problems we have found. However, this approach also comes with the limitations we have previously stated. 
This manuscript has been submitted for publication as a chapter in the Elsevier book "Mapping and Forecasting Land Use. The present and Future of Planning". Subsequent versions of this manuscript, after acceptance and review by the editorial, may have slightly different content. If accepted, the final version of this manuscript will be available via the 'Peer-reviewed Publication DOI'

\section{Developing scenarios useful for spatial and strategic planning}

The final aim of our model application is to serve the planning of Greater Sydney. To this end, the model must be able to create scenarios that display the different options of development in the region.

With the current set-up, we can produce business-as-usual scenarios. However, by including the prescriptions included in the "A Metropolis of Three Cities" region plan and the associated district plans, we can also assess the foreseeable effect that this strategic plan will have in the future of the city. For this, we need to create the spatial layers that represent the plan's prescriptions, which are not currently available. In addition, we should make those prescriptions compatible with the Metronamica conceptual model.

At the moment, the model includes a base zoning layer, according to the urban development regulations established by the Local Government Areas. These regulations are affected by the strategic plan for the whole region and, therefore, are subject to change. When creating the model scenarios, we should check that this zoning factor agrees with all other regulations and plans we want to consider in the model scenario. If not, the model will not correctly work.

\section{Conclusions}

Our work provides a next step in the development of a Land Use modelling application for Greater Sydney that can be useful for the future planning of the city ${ }^{2}$. Although the application still presents many limitations, it outperforms previous works in several aspects. It provides a higher level of detail: a spatial resolution of $100 \mathrm{x} 100 \mathrm{~m}$ cells compared to $250 \times 250 \mathrm{~m}$ cells in previous applications. It is also able to simulate more land use dynamics, differentiating between industrial, low density residential and medium-high density residential dynamics. Moreover, it includes some extra factors that were not considered in previous works, like local zoning from the regulations of Local Government Areas and the different influence of transport and activity nodes according to their relevance.

Next steps in the model application should focus on the calibration of the regional model, simulating the exchange and growth of population and jobs between regions, as well as the production of scenarios for planning purposes.

\section{Acknowledgments}

This work was supported by the Spanish Ministry of Science, Innovation and Universities and the Feder European Regional Development Fund [INCERTIMAPS PGC2018-100770B-100]; Spanish Ministry of Economy and Competitiveness and the European Social Fund [Ayudas para contratos predoctorales para la formación de doctores 2014]; University of Granada [Contratos Puente 2018]; Spanish Ministry of Science and Innovation [Ayudas para contratos Juan de la Cierva-formación 2019 - FJC2019-040043]. The first author also

\footnotetext{
2 The model application and all associated data is openly available at https://citydata.be.unsw.edu.au/
} 
This manuscript has been submitted for publication as a chapter in the Elsevier book "Mapping and Forecasting Land Use. The present and Future of Planning". Subsequent versions of this manuscript, after acceptance and review by the editorial, may have slightly different content. If accepted, the final version of this manuscript will be available via the 'Peer-reviewed Publication DOI'

appreciates the support of the University of New South Wales (City Futures Research Centre) in the development and set up of the model presented in the chapter.

\section{References}

Australian Goverment, 2011. Our Cities, Our Future.

Bunker, R., 2015. The changing political economy of the compact city and higher density urban renewal in Sydney.

Easthope, H., McNamara, N., Thompson, S., 2014. Green Square Community Survey 2014.

Easthope, H., Randolph, B., 2008. Governing the Compact City : The challenges of apartment living in Sydney.

Furtado, B.A., Ettema, D., Ruiz, R.M., Hurkens, J., van Delden, H., 2012. A cellular automata intraurban model with prices and income-differentiated actors. Environ. Plan. B Plan. Des. 39, 897-924. https://doi.org/10.1068/b37134

García-Álvarez, D., Lloyd, C.D., Van Delden, H., Camacho Olmedo, M.T., 2019. Thematic resolution influence in spatial analysis. An application to Land Use Cover Change (LUCC) modelling calibration. Comput. Environ. Urban Syst. 78, 101375. https://doi.org/10.1016/j.compenvurbsys.2019.101375

Goodspeed, R., Pelzer, P., Pettit, C., 2017. Planning our future cities: The role computer technologies can play, in: Planning Knowledge and Research. pp. 210-226. https://doi.org/10.4324/9781315308715

Greater Sydney Comission, 2018. Greater Sydney Region Plan. A Metropolis of Three Cities - connecting people.

Greater Sydney Comission, 2017. Our Greater Sydney 2056. A metropolis of three cities.

Griffith, G., 2015. The Greater Sydney Commission.

Hagen-Zanker, A., Lajoie, G., 2008. Neutral models of landscape change as benchmarks in the assessment of model performance. Landsc. Urban Plan. 86, 284-296.

https://doi.org/10.1016/j.landurbplan.2008.04.002

Hewitt, R., Van Delden, H., Escobar, F., 2014. Participatory land use modelling, pathways to an integrated approach. Environ. Model. Softw. 52, 149-165. https://doi.org/10.1016/j.envsoft.2013.10.019

Hu, R., 2012. Shaping a global sydney: The city of sydney's planning transformation in the 1980s and 1990s. Plan. Perspect. 27, 347-368. https://doi.org/10.1080/02665433.2012.681139

Infrastructure New South Wales, 2018. Building Momentum. State Infrastructure Strategy 2018-2038.

Kim, D., Batty, M., 2011. Calibrating Cellular Automata Models for Simulating Urban Growth: Comparative Analysis of SLEUTH and Metronamica, Ucl Working Papers Series.

Lahti, J., 2008. Modelling Urban Growth Using Cellular Automata: A case study of Sydney, Australia.

Lieske, S.N., van den Nouwelant, R., Han, J.H., Pettit, C., 2021. A novel hedonic price modelling approach for estimating the impact of transportation infrastructure on property prices. Urban Stud. 58, 182-202. https://doi.org/10.1177/0042098019879382

Liu, Y., 2009. Modelling Urban Development with Geographical Information Systems and Cellular Automata. CRC Press.

Liu, Y., Feng, Y., 2012. A logistic based cellular automata model for continuous urban growth simulation: A case study of the Gold Coast City, Australia, in: Agent-Based Models of Geographical Systems. pp. 643-662. https://doi.org/10.1007/978-90-481-8927-4_32 
This manuscript has been submitted for publication as a chapter in the Elsevier book "Mapping and Forecasting Land Use. The present and Future of Planning". Subsequent versions of this manuscript, after acceptance and review by the editorial, may have slightly different content. If accepted, the final version of this manuscript will be available via the 'Peer-reviewed Publication DOI'

Liu, Y., Phinn, S., 2005. Modelling the driving forces OF Sydney's urban development (1971-1996) in a cellular environment. Appl. GIS 1. https://doi.org/10.2104/ag050027

Liu, Y., Phinn, S.R., 2004. Mapping the urban development of Sydney (1971-1996) with cellular automata in a GIS environment. J. Spat. Sci. 49, 57-74. https://doi.org/10.1080/14498596.2004.9635022

Morris, A., 2018. The financialisation of housing and the housing affordability crisis in Sydney. Hous. Financ. Int. 63-69.

NSW Department of Planning, 2005. City of Cities. A Plan for Sydney's Future. Sydney.

NSW Government, 2018. Future Transport Strategy 2056. https://doi.org/10.1038/4541030b

NSW Government, 2014. A plan for growing sydney.

Páez, D., Escobar, F., 2017. Urban Transportation Scenarios in a LUCC Model: A Case Study in Bogota, Colombia, in: Camacho Olmedo, M.T., Paegelow, M., Mas, J.-F., Escobar, Francisco (Eds.), Geomatic Approaches for Modeling Land Change Scenarios. Springer, Cham, Switzerland, pp. 367-398. https://doi.org/10.1007/978-3-319-60801-3_18

Pettit, Christopher, Biermann, S., Pelizaro, C., Bakelmun, A., 2020. A Data-Driven Approach to Exploring Future Land Use and Transport Scenarios: The Online What If? Tool. J. Urban Technol. 27, 21-44. https://doi.org/10.1080/10630732.2020.1739503

Pettit, Chris, Shi, Y., Han, H., Rittenbruch, M., Foth, M., Lieske, S., van den Nouwelant, R., Mitchell, P., Leao, S., Christensen, B., Jamal, M., 2020. A new toolkit for land value analysis and scenario planning. Environ. Plan. B Urban Anal. City Sci. 47, 1490-1507. https://doi.org/10.1177/2399808320924678

Pinnegar, S., Randolph, B., 2012. Renewing the West: Prospects for urban regeneration in Sydney 's western suburbs.

RIKS, 2012. Metronamica Documentation. Maastricht.

Santé, I., García, A.M., Miranda, D., Crecente, R., 2010. Cellular automata models for the simulation of realworld urban processes: A review and analysis. Landsc. Urban Plan. 96, 108-122. https://doi.org/10.1016/j.landurbplan.2010.03.001

The Committee for Sydney, 2017. Planning for the city we want. Submission to the Greater Sydney Commission. Draft District Plans and Towards Our Greater Sydney 2056.

Tong, X., Feng, Y., 2020. A review of assessment methods for cellular automata models of land-use change and urban growth. Int. J. Geogr. Inf. Sci. 34, 866-898. https://doi.org/10.1080/13658816.2019.1684499

Troy, L., Randolph, B., Crommelin, L., Easthope, H., Pinnegar, S., Troy, B.L., Randolph, B., Crommelin, L., Easthope, H., Pinnegar, S., 2015. Renewing the Compact City urban redevelopment Final Report.

Van Delden, H., Hurkens, J., 2011. A generic Integrated Spatial Decision Support System for urban and regional planning, in: Chan, F., Marinova, D., Anderssen, R.S. (Eds.), 19th International Congress on Modelling and Simulation. Perth, pp. 127-139.

Van Delden, H., Hurkens, J., Shi, Y., Vanhout, R., Van Vliet, J., 2012. WISE - Waikato Integrated Scenario Explorer, User Manual (Version 1.2.0).

Van Delden, H., Van Vliet, J., Rutledge, D.T., Kirkby, M.J., 2011. Comparison of scale and scaling issues in integrated land-use models for policy support. Agric. Ecosyst. Environ. 142, 18-28. https://doi.org/10.1016/j.agee.2011.03.005

Van Delden, H., Vanhout, R., 2018. A Short Presentation of Metronamica, in: Camacho Olmedo, M.T., Paegelow, M., Mas, J.-F., Escobar, F. (Eds.), Geomatic Approaches for Modeling Land Change Scenarios. Springer, Cham, Switzerland, pp. 511-519. https://doi.org/https://doi.org/10.1007/978-3319-60801-3_38

Van Delden, H., Vanhout, R., Clarke, K.C., Van Vliet, J., Verburg, P.H., 2018. A Short Presentation of Metronamica, in: Camacho Olmedo, M.T., Paegelow, M., Mas, J.-F., Escobar, F. (Eds.), Geomatic Approaches for Modeling Land Change Scenarios. Springer, Cham, Switzerland, pp. 485-492. 
This manuscript has been submitted for publication as a chapter in the Elsevier book "Mapping and Forecasting Land Use. The present and Future of Planning". Subsequent versions of this manuscript, after acceptance and review by the editorial, may have slightly different content. If accepted, the final version of this manuscript will be available via the 'Peer-reviewed Publication DOI'

https://doi.org/https://doi.org/10.1007/978-3-319-60801-3_34

Van Vliet, J., Bregt, A.K., Brown, D.G., Van Delden, H., Heckbert, S., Verburg, P.H., 2016. A review of current calibration and validation practices in land-change modeling. Environ. Model. Softw. 82, 174182. https://doi.org/10.1016/j.envsoft.2016.04.017

Van Vliet, J., Bregt, A.K., Hagen-Zanker, A., 2011. Revisiting Kappa to account for change in the accuracy assessment of land-use change models. Ecol. Modell. 222, 1367-1375. https://doi.org/10.1016/j.ecolmodel.2011.01.017

Van Vliet, J., Hagen-Zanker, A., Hurkens, J., Van Delden, H., 2013. A fuzzy set approach to assess the predictive accuracy of land use simulations. Ecol. Modell. 261-262, 32-42. https://doi.org/10.1016/j.ecolmodel.2013.03.019

Van Vliet, J., Hurkens, J., White, R., Van Delden, H., 2012. An activity-based cellular automaton model to simulate land-use dynamics. Environ. Plan. B Plan. Des. 39, 198-212. https://doi.org/10.1068/b36015

White, R., Engelen, G., Uljee, I., 1997. The use of constrained cellular automata for high-resolution modelling of urban land-use dynamics. Environ. Plan. B Plan. Des. 24, 323-343. https://doi.org/10.1068/b240323

Wu, F., Martin, D., 2002. Urban expansion simulation of Southeast England using population surface modelling and cellular automata. Environ. Plan. A 34, 1855-1876. https://doi.org/10.1068/a3520

Wu, J., Mohamed, R., Wang, Z., 2011. Agent-based simulation of the spatial evolution of the historical population in China. J. Hist. Geogr. 37, 12-21. https://doi.org/10.1016/j.jhg.2010.03.006 